\section{Assessment of the farm management of culling cattle: a survey of existing practices and suggestions for drafting of best practices}

\author{
Alessandro Russo Frattasi, \\ Lorenzo Cesano,' Michelangelo Botta, \\ Daniele Pattono \\ 'Divisione di Ispezione degli Alimenti di \\ Origine Animale, Dipartimento di Scienze \\ Veterinarie, Università degli Studi di \\ Torino, Grugliasco (TO); \\ ${ }^{2}$ ASL CN1, Dipartimento di Prevenzione, \\ Fossano (CN), Italy
}

\section{Abstract}

The aim of this study is to evaluate different aspects regarding culled cattle and to suggest operating procedures for their correct management. Information collected in Piedmont region allowed for an assessment of the number of cattle put down on the farm, a quantification of slaughters performed in urgency and emergency (SUS/SES) and a headcount of those which died during farming. The survey highlighted the limited use of euthanasia or putting down compared to the number of cases of SUS/SES which were approximately ten times higher. If cattle displays severe health problems, such as a multifactorial disease like downer cow, the farmer has to decide rapidly the treatment to avoid cattle distress. A checklist has been developed and a flow chart has been revised to assist farmers and vets to quicken the decision-taking process and to manage the cattle in a more efficient manner. During this study a number of different problems have been stressed out. Particularly, the shortcomings in the training of operators commissioned to manage the animals, the inadequacy of structures used for the sheltering and slaughter of bovines on the farm, and differences in the operating procedures for culled cattle across the territory. From the obtained results, we can conclude that it is necessary to adopt a transversal approach, so that the information regarding these animals (welfare, health status, drug treatments and destination) will be uniform and adequate during all the steps of production, to ensure animal welfare and food safety.

\section{Introduction}

Every animal, according to the five freedoms of animals redefined in 1993 by the Farm Animal Welfare Council, has the right to have a health treatment and not to suffer unnecessarily (FAWC, 1993). Sometimes an animal at the end of its career is left without all the necessary attentions and this is contrary to the Universal Declaration of Animal Rights, arts. 2, 3 and 9 , signed in 1978 by the United Nations Educational, Scientific and Cultural Organization (UNESCO). These concepts are also expressed by European and national standards in animal welfare and abuse (EEC Decision 78/923/CE; European Commission, 1978, 2001). The first three freedoms (freedom from hunger, thirst and malnutrition; availability of appropriate and comfortable shelter; prevention, diagnosis and prompt treatment of injuries and diseases) are universally recognised and applied by farmers or are, naturally, within the competence of the veterinary practitioner. The last two (freedom to express species-specific behaviour, freedom from fear and stress) (UNESCO, 1978) are rights that are not always easy to understand, but they must nevertheless be considered and guaranteed by all stakeholders and by the veterinary pratictioner with the implementation of all measures. For these reasons, it is compulsory to prevent the animals from experiencing pain during and at the end of their productive life. One of the main difficulties to cope with is, in fact, finding the right way to ensure an adequate standard of welfare also at the end of the production cycle of the livestock. As reported in the literature, an animal that is unable to stand up is defined as a downer or culled cow. There are many diseases that can cause weakness and an inability to move or to stand up: electrolyte imbalances, dysfunction and inflammation of the gastrointestinal tract, metabolic syndrome (puerperal, fat cow syndrome), nerve damage, respiratory problems, trauma, neoplasia, etc. (Green et al., 2008; Kalaitzakis et al., 2010; Pautasso et al., 2011). Table 1 shows the most common diseases that can lead to having a downer cow and the clinical signs thereof.

All these events may affect the animal individually or in combination, leading to a rapid decay of the welfare status and of the quality of the meat. When an animal is on the ground, the shorter the period of the decubitus, the greater the chance is that it will be able to move again; the longer the decubitus, the more unfavorable the prognosis (Stull et al., 2007).

In our opinion the specific task of food business operator (FBO) and of veterinarians (public and private) working in the field of livestock is to ensure the correct management of these animals. In case of a wounded animal or a minor injury you can proceed with special emergency slaughtering (SES), ensuring proper transportation, the respect of welfare rules and, if necessary, the stunning on the truck at
Correspondence: Daniele Pattono, Divisione di Ispezione degli Alimenti di Origine Animale, Dipartimento di Scienze Veterinarie, Università degli Studi di Torino, via Leonardo da Vinci 44, 10095 Grugliasco (T0), Italy.

Tel. +39.011.6709217 - Fax: +39.011.2369217.

E-mail: daniele.pattono@unito.it

Key words: Cattle, Culled animals, Animal welfare, Emergency slaughter, Animal transport.

Received for publication: 29 March 2013. Accepted for publication: 12 October 2013.

This work is licensed under a Creative Commons Attribution 3.0 License (by-nc 3.0).

(OCopyright A. Russo Frattasi et al., 2014 Licensee PAGEPress, Italy

Italian Journal of Food Safety 2014; 3:1540

doi:10.4081/ijfs.2014.1540

the time of slaughter. In case an animal is not able to walk (without feeling pain, or if there are signs of suffering), the operators should proceed to a special urgency slaughtering (SUS) or to euthanasia and subsequent disposal as ruled in the Regulation (EC) No 1069/2009 (European Commission, 2009).

If the FBO opts for an SES, the transport itself may be a threat to animals. For this reason it is prohibited to move animals that fall under such categories as the following: cows in late pregnancy, animals with neurological syndromes, etc. (Pautasso et al., 2011; European Commission, 2005). The decision needs to be taken rapidly because in this situation, if prolonged even for a short time, the animals may experience much pain and suffering. A rapid decision leads to animal welfare of a better quality, and less economic damage to the farmers.

According to the notes of the Piedmont Region (2007), taken recently into account also by the Italian Ministry of Health in a document dated 15 March 2012 regarding the suitability of transport to slaughterhouse of animals (Italian Ministry of Health, 2012), in the case of downer cows the competent authorities may allow the transport applying, without exceptions, to the requirements of Annex I, Chapter 1, Section 2 of the Regulation (EC) No 1/2005 (European Commission, 2005). If the animal can walk, even with some difficulties but without necessarily strong pain, it can be allowed to be transported in accordance with Annex I, Chapter 1, Section 3 of Regulation (EC) No 1/2005 (European Commission, 2005), only after evaluation done by the veterinarian.

As far as the destiny of meats coming from SES/SUS animals is concerned, the following inspective judgement regarding the commercialisation of the meat is asked of the veteri- 
nary officer of the establishment where the animal was slaughtered. Following the postmortem inspection, the vet will decide whether the meat should be commercialised, whether ulterior analyses should be carried out (e.g. batteriological/chemical analyses), or whether it should be considered as animal by-product.

The aim of this work is to evaluate the number of animals in retirement in two districts of the Piedmont region, to assess if there are critical issues in the management of those animals and, finally, to propose a practical checklist to assess their future destination (SES or SUS) in order to avoid unnecessary suffering.

\section{Materials and Methods}

We collected data regarding the number of animals killed on the farm and that of animals slaughtered with SUS and SES in the Local Sanitary Service (azienda sanitaria locale, ASL) CN1 in 2010 with the help of the veterinary officers. After the first analysis, we proceeded to collect data by count of taxes due for the carcass destruction.

We analysed the data (Table 2) related to animals which died on farms on the territory of ASL CN1 and T03. From a total number of 25,064 animals that died in Piedmont region during 2010, 5519 certificates were considered (from the former districts ASL 17/2 in Saluzzo, Cuneo district MIAC and ASL T03 district Cavour-Vigone). The data were collected through the counting of certificates for the transport of dead animals found in the abovementioned districts and by summing the veterinarian certificates that were registered at the carcass treatment plants.

\section{Results and Discussion}

Out of a total of 14,666 animals that died in the farms, the number of euthanised animals corresponded to about $1 \%(\mathrm{n}=101$, animals killed), while the special slaughtering were ten times higher with a number equal to 727 SUS and 225 SES ( $n=952$, animals at SUS/SES). This data made us suspect that FBO used the euthanasia or killing only in extreme cases (1.6\% total), while in case of opportunity special slaughterings (SUS or SES) were more frequently used. Collecting data was extremely difficult due to the lack of certificates, as they were not available. We can presume that the numbers do not correspond to the real needs and it may happen that the breeder does not require the intervention of the veterinarian and the animal comes to death after a more or less long agony.

This work was conducted with a comparison of the records of slaughter of the computerised database of the Piedmont region and by interviews with colleagues responsible for slaughterhouses authorised to SUS and territories of origin of the animals sent to SUS. The work highlighted some weaknesses/critical issues subject of the study, which could be improved: i) differences in the classification of cases or an incomplete in farm diagnosis of downer cows; ii) differences in the collection of data on a centralised database system for the analysis and quantification of the SUS/SES and euthanasia; iii) lack in the training of operators (both in farming and in special slaughter) about the good practices for downer cows; iv) inadequacy of structures for shelter or slaughter of animals on farms; v) lack of attention of veterinarians (public and private) during the check up in order to establish more clearly the diagnosis of the downer cows; vi) lack of good handling practices and information about systems, procedures and timing of both the ani- mals and transport of carcasses.

For this reasons and for a rapid and unambiguous management of the animals at the end of their career, we propose a flowchart (Figure 1) and a check-list (Supplementary Table 1) suitable for the on field analysis.

The flow chart starts from a previous work done by the Piedmont region for the management of downer cows, as mentioned previously, and has been elaborated by the Authors. When an animal in retirement is experiencing problems that prevent it from standing up and force it to be stationary on the ground, a decision has to be taken very rapidly, as mentioned above. In our opinion, the first step is to assess the state of consciousness of the animal, according to the parameters summarised in Table 3 . The parameters proposed can be easily checked and allow to quickly understand the status of normal or altered consciousness of the animal, as well as verifying the correct presence of some great organic functions key. This leads the veterinarian to make a clear distinction between alert and non-alert animals. Non-alert animals will be euthanised and their carcass destroyed and alert animals will be evaluated to see if they can be transported. If this is the case, SES will be carried out but if they cannot be transported, a careful veterinary evaluation will be done on the animal's clinical status, and a decision regarding euthanasia or SUS will be taken.

The adoption of the proposed checklist (Supplementary Table 1), which reiterates the determination of consciousness (alert/nonalert) as the first assessment and the consequent different management options, can facilitate the on field practice. The checklist proposes in the first part, general assessment, all the parameters useful to make a first screening on the possibility of assigning it to human consumption or to slaughter and to the destruction cycle. In the evaluation of the clinical signs of the animal section other indexes

Table 1. Major diseases affecting downer cows.

\begin{tabular}{ll} 
Pathology & Clinical signs \\
$\begin{array}{l}\text { Hypocalcemia (milk fever) } \\
\begin{array}{l}\text { Dysfunction and inflammation of the gastrointestinal tract } \\
\text { (e.g. abomasal ulcer) }\end{array}\end{array}$ & $\begin{array}{l}\text { Dizziness, muscle twitching, tremors, mydriasis } \\
\text { Acute abdomen, loss of appetite, pale mucous membranes, loose stools/diarrhea, melena, }\end{array}$ \\
\hline $\begin{array}{l}\text { Metabolic imbalances (alkalosis/metabolic acidosis); } \\
\text { fat cow syndrome (hepatic steatosis/ fatty liver) }\end{array}$ & $\begin{array}{l}\text { Tiredness, muscle weakness, recumbency forced, } \\
\text { anorexia, loss of production, hepatomegaly (increased liver dullness projection area) }\end{array}$ \\
Pathologies of central nervous system & $\begin{array}{l}\text { Sensory alterations (depression, stupor, coma, hyper-excitability, aggression), nystagmus, } \\
\text { strabismus, anisocoria, head turned, trismus, tetra/paraplegia, abnormal gait, behaviour } \\
\text { changes }\end{array}$ \\
\hline $\begin{array}{l}\text { Breathing problems } \\
\text { Infectious diseases; generalised or localised processes }\end{array}$ & $\begin{array}{l}\text { Shortness of breath, abdominal breathing } \\
\text { Different manifestations according to the different etiological agents } \\
\text { (e.g. E. coli, } \text { Cl. tetani, L. monocytogenes) }\end{array}$ \\
$\begin{array}{l}\text { Injury-related processes and limbs pain } \\
\text { Post-partum diseases and related injuries }\end{array}$ & $\begin{array}{l}\text { Skin lesions, bruises, inflammatory edema, hematomas, discontinuity limbs, laminitis } \\
\text { Signs of trauma, bruise, limbs pains, inability to stand up, fever, vaginal discharge, polipnea }\end{array}$ \\
\hline
\end{tabular}


are present in order to better understand the clinical status of the animal and, on the basis of the findings, actually decide how to proceed. This checklist could be a useful tool for all actors in the supply chain in order to: i) create a database useful to identify and classify the problems encountered in culled animals (areas A and C); ii) help the veterinary officer in the slaughtering process, regarding postmortem judgment (area B); iii) provide tools to primary production/breeders to reduce and prevent the development of situations difficult to manage and animal abuse (primary production).

\section{Conclusions}

Animal management at the end of a career is a great concern for all the operators. Consequently, it requires more effort from everyone who interacts at various levels and titles in farming and slaughter (FBOs, public and private veterinarians) in order to ensure food safety and animal welfare. Given the complexity and the difficulties of the problem, we suggest a standardisation of operating procedures. This effort can lead to a standardisation of the management of these animals during all the steps (breeding, transport and slaughtering). It may be useful, as already suggested above, to develop a system for collecting data either on animals at the end of their career and downer cows in the farm. This system should give a precise quantification of the actual situation. The development of a checklist is certainly a useful tool for collecting data and taking decisions. This system can be implemented by the assignment of a score for each point and the final addition can allow rapid classifications in order to avoid unnecessary suffering. In case the animal is destined to be slaughtered, it would be very useful to collect into a regional or national database the information gathered about the health status of the herd, with the final judgment after death (especially in the case of exclusion from human consumption). All the data may be provided to the competent authority and provide for the identification of the causes of downer cows, so as to begin having data on which to promote best practices and management manuals.

Last but not least, all data allows a system of refunds by insurance companies to avoid the use of other forms of slaughter and achieving in this way a reduction of unnecessary suffering and a more friendly opinion on farm practices.
Table 2. Dying and culling of animals in sample farms of various local sanitary services in 2010.

\begin{tabular}{lccc}
\hline ASL & Dead animals (n) & Animals culled on farm (n) & $\%$ \\
ASL CN1- Saluzzo district & 3264 & 40 & 1.22 \\
Cuneo MIAC district & 666 & 17 & 2.55 \\
\hline ASL TO3- Cavour-Vigone district & 1589 & 32 & 2.01 \\
Total & 5519 & 89 & 1.61 \\
\hline
\end{tabular}

ASL, azienda sanitaria locale (local sanitary service). Data are obtained by counting the documents for the transport of dead animals found in the districts analysed.

Table 3. Classification alert to assess the state of consciousness of the animal.

\begin{tabular}{lll} 
Classification & Animal aspect & Destination \\
Alert vigilant & $\begin{array}{l}\text { Conscious; } \\
\text { Attention to the surrounding environment; }\end{array}$ & Eventual slaughter (SUS/SES) \\
& $\begin{array}{l}\text { Responds to stimuli of mild/medium; } \\
\text { intensity appetite and feeding maintained }\end{array}$ & \\
\multirow{2}{*}{$\begin{array}{l}\text { Non-alert } \\
\text { not vigilant }\end{array}$} & $\begin{array}{l}\text { Unconscious; } \\
\text { Does not respond to the surrounding environment; slaughter-euthanasia } \\
\end{array}$ & $\begin{array}{l}\text { Responds only to very intense stimulation } \\
\text { appetite and eating little or not }\end{array}$ \\
\end{tabular}

SUS, special urgency slaughtering; SES, special emergency slaughtering.

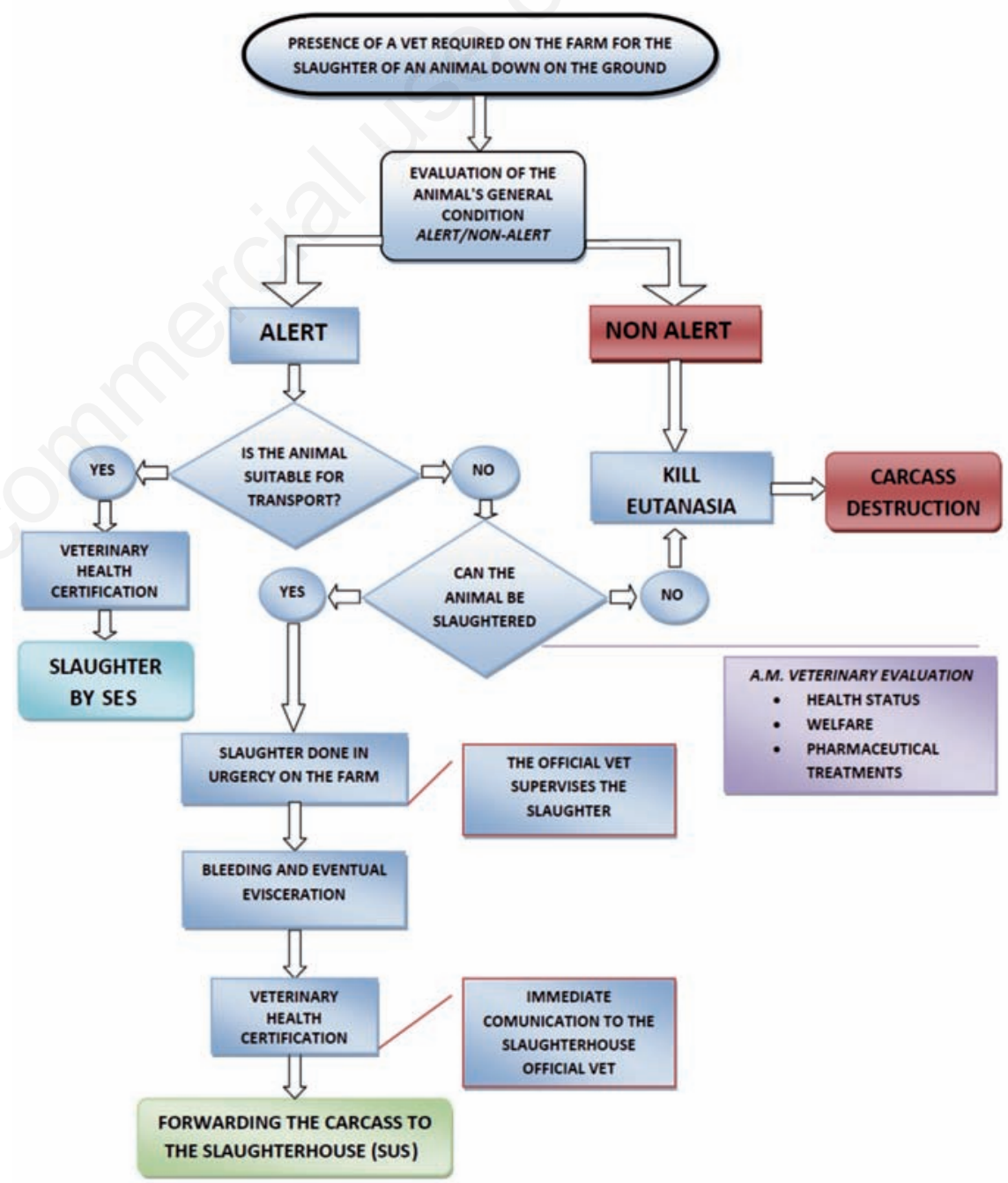

Figure 1. Flowchart relative to the operative indications in case of animals down on the ground applying Reg. (EC) N. 1/2005 on the protection of animals during trasport and related operations (modified from Piedmont Region, 2007). 
ucts and derived products not intended for human consumption and repealing Regulation (EC) n. 1774/2002 (Regulation on animal by-products), 1069/2009/EC. In: Official Journal, L 300/1, 14/11/2009.

FAWC, 1993. Second report on priorities for research and development in farm animal welfare. Farm Animal Welfare Council Publ., Tolworth, UK.

Green L, Lombard JE, Garber LP, Wagner BA, Hill GW, 2008. Factors associated with occurrence and recovery of nonambulatory dairy cows in the United States. J Dairy Sci 91:2275-83.

Italian Ministry of Health, 2012. Department of veterinary public health, food safety and the governing bodies for the protection of health (DGSA-DGSA) ministerial note, Prot. N. 0008524-P 3/15/2012. Suitability of animal welfare for transport to the slaughterhouse. Regulation (EC) n. 1/2005 art. 3, EC Regulation 854/2004, Annex I, Section I, Chapter II, point C. Ministry of Health Publ., Rome, Italy.

Kalaitzakis E, Panousis N, Roubies N, Giadinis
N, Kaldrymidou E, Georgiadis M, Karatzias $\mathrm{H}, 2010$. Clinicopathological evaluation of downer dairy cows with fatty liver. Vet $\mathbf{J}$ 51:615-22.

Pautasso A, Iulini B, D’Angelo A, Bellino C, Dondo AA, Tursi M, Current M, Greek MF, Pintore MD, Bozzetta E, Maurella C, Casalone C, 2011. Syndrome of the cow on the ground: clinical diagnostic monitoring system in Piedmont. Large Anim Rev 17:83-8.

Piedmont Region, 2007. Regional Prot. 1242527/03 of 19/09/2007. Transport of animals that are unable to move independently without pain or to walk unassisted. Additional information. Piedmont region Publ., Turin, Italy.

Stull CL, Payne MA, Berry S, Reynolds JP, 2007. A review of the causes, prevention and welfare of nonambulatory cattle. J Am Vet Med Assoc 231:227-34.

UNESCO, 1978. Universal declaration of animal rights of 15.10.1978. United Nations Educational, Scientific and Cultural Organization Publ., Paris, France. 